\title{
Cranioplasty after decompressive craniectomy: An institutional audit and analysis of factors related to complications
}

\author{
Zain A. Sobani \\ Aga Khan University \\ Muhammad Shahzad Shamim \\ Aga Khan University, shahzad.shamim@aku.edu \\ Syed Nabeel Zafar \\ Aga Khan University \\ Mohsin Qadeer \\ Aga Khan University, mohsin.qadeer@aku.edu \\ Najiha Bilal \\ Aga Khan University
}

See next page for additional authors

Follow this and additional works at: https://ecommons.aku.edu/pakistan_fhs_mc_surg_neurosurg

Part of the Neurology Commons, Neurosurgery Commons, and the Surgery Commons

\section{Recommended Citation}

Sobani, Z., Shamim, M., Zafar, S., Qadeer, M., Bilal, N., Murtaza, S., Enam, A., Bari, M. (2011). Cranioplasty after decompressive craniectomy: An institutional audit and analysis of factors related to complications. Surgical Neurology International, 2, 123.

Available at: https://ecommons.aku.edu/pakistan_fhs_mc_surg_neurosurg/19 


\section{Authors}

Zain A. Sobani, Muhammad Shahzad Shamim, Syed Nabeel Zafar, Mohsin Qadeer, Najiha Bilal, Syed Ghulam Murtaza, Ather Enam, and Muhammad Ehsan Bari 


\section{Original Article}

\section{Cranioplasty after decompressive craniectomy: An institutional audit and analysis of factors related to complications}

Zain A. Sobani, Muhammad Shahzad Shamim, Syed Nabeel Zafar, Mohsin Qadeer, Najiha Bilal, Syed Ghulam Murtaza, Syed Ather Enam, Muhammad Ehsan Bari

Department of Surgery, Section of Neurosurgery, Aga Khan University Hospital, Karachi, Pakistan

E-mail: Zain A. Sobani - zsobani@gmail.com; *Muhammad Shahzad Shamim - shahzad.shamim@aku.edu; Syed Nabeel Zafar - nabeel.zafar@aku.edu; MohsinQadeer - mohsin.qadeer@aku.edu; Najiha Bilal -najiha.farooqi@gmail.com; Syed GhulamMurtaza - ghulam.murtaza@aku.edu; Syed AtherEnam - ather.enam@aku.edu; Muhammad Ehsan Bari - ehsan.bari@aku.edu

*Corresponding author

Received: II May II

Accepted: I5 August II

Published: 17 September II

This article may be cited as:

Sobani ZA, Shamim MS, Zafar SN, Qadeer M, Bilal N, Murtaza SG, et al. Cranioplasty after decompressive craniectomy: An institutional audit and analysis of factors related to complications. Surg Neurol Int 2011;2:123.

Available FREE in open access from: http://www.surgicalneurologyint.com/text.asp?201 I/2/1/123/85055

Copyright: $@ 201$ I Sobani ZA. This is an open-access article distributed under the terms of the Creative Commons Attribution License, which permits unrestricted use, distribution, and reproduction in any medium, provided the original author and source are credited.

\section{Abstract}

Background: Although a relatively simple procedure, cranioplasties have been associated with high complication rates. Keeping this in perspective, we aimed to determine the factors associated with immediate and long-term complications of cranioplasties at our institution.

Methods: A retrospective review of patient records was carried out for patients having undergone reconstructive cranioplasties at our institution during the last 10 years (2001-2010). All case notes, records, and investigations were reviewed and the data were recorded in a predesigned questionnaire. Complications were recorded along with existing comorbids and measures taken for their prevention and management. Univariate and multivariate logistic regression analysis was performed to determine possible predictors of complications.

Results: A total of 96 patients with a mean age of $33+15$ years were included in the study. Of the sample, $76 \%(n=73)$ had no comorbids. The leading primary pathology was blunt traumatic brain injuries in $46 \%(n=44)$, followed by cerebrovascular incidents in $24 \%(n=23)$, penetrating traumatic brain injuries in $12 \%(n=11)$, and tumors in $10 \%(n=10)$ of cases, with $41 \%(n=39)$ of patients requiring multiple craniotomies. In a mean follow-up of $386 \pm 615$ days, complications were noted in $36.5 \%(n=35)$ of the patients. Twenty six percent of patients $(n=25)$ had minor complications which included breakthrough seizures $(15.6 \%, n=15)$, subgaleal collections $(3.1 \%, n=3)$, and superficial wound infections $(3.1 \%, n=3)$, whereas major complications $(10.4 \% \mathrm{n}=10)$ included hydrocephalus $(3.1 \%, \mathrm{n}=3)$, transient neurological deficits $(3.1 \%, n=3)$, and osteomyelitis $(2.1 \%, n=2)$. Univariate and multivariate analysis revealed External Ventricular Drain (EVD) placement and parietal flaps to be associated with complications. This could be explained by the fact that the patients requiring EVD usually have relatively severe head injuries, increasing the possibility of hydrocephalus.

Conclusion: We have found a higher risk of complications of cranioplasty in patients who had EVD placement and removal prior to their constructive surgery. We however did not find any association between risks of complications in any

\begin{tabular}{|l|}
\hline \multicolumn{1}{|c|}{$\begin{array}{c}\text { Access this article } \\
\text { online }\end{array}$} \\
\hline $\begin{array}{l}\text { Website: } \\
\text { www.surgicalneurologyint.com }\end{array}$ \\
\hline DOI: \\
10.4103/2152-7806.85055 \\
\hline $\begin{array}{l}\text { Quick Response Code: } \\
\end{array}$ \\
\hline
\end{tabular}


other studied variable. We also did not find any association between intraoperative placement of subgaleal drains and postoperative risk of subgaleal fluid collections. Overall, our results are comparable with other reported series on cranioplasties.

Key Words: Decompressive craniectomy [E04.188.200], reconstructive cranioplasty

\section{INTRODUCTION}

Decompressive craniectomies have been demonstrated as an effective modality in reducing intracranial pressure (ICP) in emergency situations involving severe head injuries, ${ }^{[4,6,13,15]}$ strokes, ${ }^{[11,14,20,21]}$ hemorrhages, ${ }^{[12,18]}$ infections, and tumors. ${ }^{[1]}$ By removing the bone flap and expanding the dura, a space can be created for the bulging brain freeing it from the confines of the cranial vault and subsequent pressure effects. A linear relationship has been demonstrated between the size of craniectomy and the associated decrease in ICP. ${ }^{[17]}$

However, in the long run, alterations in hemodynamics, venous drainage, cerebrospinal fluid (CSF) dynamics, and general metabolic function have been demonstrated along with gradual neurological decline. ${ }^{[23]}$ This neurologic deterioration in patients with cranial defects has been attributed to the effect of atmospheric pressure on the scalp flap, and is effectively treated by restoring the cranial compartment to its "closed" state. Nearly $88 \%$ of patients who presented with a sunken skin craniectomy flap and moderate neurologic deficit demonstrated neurologic improvement after the repair of the cranial defect or cranioplasty. ${ }^{[23]}$ Xenon computed tomography studies have also demonstrated improved venous outflow and CSF systolic flow velocity after this procedure. ${ }^{[8]}$ Therefore, stable patients with normal ICPs require a cranioplasty not just for cosmetic reasons. Although the procedure of cranioplasty is a relatively simple one, it has been shown to have a high relative complication rate. ${ }^{[5,9,19]}$ Keeping this high complication rate in perspective, a retrospective audit of our institution was carried out in order to determine the factors associated with immediate and long-term complications of cranioplasties in our setting.

\section{MATERIALS AND METHODS}

A retrospective review of patient records was carried out for patients having undergone reconstructive cranioplasties at our institution during the last 10 years (2001-2010). Patients of all age groups undergoing cranioplasty procedures following decompressive craniectomy for intractable intracranial hypertension were included in the study. The cases were included regardless of the material used for cranioplasty, i.e., patients having undergone cranioplasties with autologous bone, polymethylmethacrylate (PMMA), autologous bone with PMMA, and autoclaved autologous bone were included in the study. Cranioplasties performed for infected post-craniotomy bone flaps, post-trauma cranial defects, bone involved with tumors, and those done for cosmetic reasons, not preceded by a decompressive surgery, were not included. In cases where autologous bone flaps were used, the bone flaps were either stored in an anterior abdominal wall subcutaneous pocket or in a $-26^{\circ} \mathrm{C}$ freezer. All cranioplasties were performed by either senior residents or chief residents, supervised by one of five credentialed neurosurgeons. The technique remained largely same over the study period with only minor variations depending upon surgeons' preferences and individual cases.

All case notes, records, and investigations were reviewed and the data were recorded in a predesigned questionnaire. Follow ups including complications were recorded along with the measures taken for their management. Descriptive analysis was performed by calculating means and standard deviations for continuous variables and proportions for categorical ones. All major complications (Subdural Hematoma [SDH], Extradural Hematoma [EDH], Osteomyelitis, Neurological deficits) were clumped into a binary variable, i.e., yes/no. To determine factors associated with the occurrence of complications, we first performed univariate analysis using logistic regression and tabulated odds ratios with 95\% confidence intervals. A multivariate logistic regression model was then constructed including all variables with $P$ values $<0.25$ upon univariate analysis and clinically relevant variables which were determined a priori by the authors. The data were analyzed using Statistical Package for Social Sciences version 17 (International Business Machines, Armonk, New York).

\section{RESULTS}

A total of 96 patients met the above criteria and were included in the study. Analysis of the data revealed a mean age of $33 \pm 14.8$ years, $72.9 \%(\mathrm{n}=70)$ of our patients were males, 27.1\% $(\mathrm{n}=26)$ were females. Of the sample, 76\% (n = 73) had no known comorbids, the rest had one or two comorbids, and seven patients had multiple $(>2)$ comorbidities. The leading primary pathology was blunt traumatic brain injuries in $45.8 \%$ $(\mathrm{n}=44)$, followed by cerebrovascular incidents in $23.95 \%$ $(\mathrm{n}=23)$, penetrating traumatic brain injuries in $11.5 \%$ $(\mathrm{n}=11)$, and tumors in $10.4 \%(\mathrm{n}=10)$ of cases, with 
$40.6 \%$ ( $\mathrm{n}=39$ ) of patients requiring more than one cranial procedures. Nearly all $(97.9 \%, \mathrm{n}=94)$ index surgeries were performed at our center and the rest were performed elsewhere and referred to us for further management. The various flaps used included standard trauma $(59.4 \%, \mathrm{n}=57)$, frontal $(16.7 \%, \mathrm{n}=16)$, parietal $(13.5 \%, \mathrm{n}=13)$, and temporal $(9.4 \%, \mathrm{n}=9)$ flaps. Of these, $82.3 \%(\mathrm{n}=79)$ were unilateral and the rest $(15.6 \%, \mathrm{n}=15)$ were bilateral. The craniotomy bone flaps were preserved in $85.4 \%(\mathrm{n}=82)$ of cases using cryopreservation in $76 \%(\mathrm{n}=73)$ and subcutaneous preservation in $9.4 \%(\mathrm{n}=9)$, whereas $14.6 \%(\mathrm{n}=14)$ were damaged or discarded.

Reconstructive cranioplasties were performed as a separate hospital admission in $79.2 \%(\mathrm{n}=76)$ of the patients, whereas in $20.8 \%(\mathrm{n}=20)$ patients, it was carried out during the same admission. The reconstructive procedure was performed after a mean delay of $90 \pm$ 116 days. Mean preoperative Glasgow coma scale (GCS) score of the patients undergoing cranioplasties was 12 \pm 3.06 and they were operated at mean hemoglobin of $12 \pm 1.32 \mathrm{mg} / \mathrm{dl}$. At the time of the cranioplasty, $31.2 \%(\mathrm{n}=30)$ patients had their airway maintained through tracheostomies, $11.5 \%(\mathrm{n}=11)$ were receiving nutrition through gastrostomy tubes, and $2.1 \%(\mathrm{n}=2)$ patients had ventriculoperitoneal (VP) shunts placed. Intravenous cefazolin (first generation cephalosporin) was the most commonly administered prophylactic antibiotic, administered to $87.5 \%(\mathrm{n}=84)$ of the patients, while the remaining received other antibiotics depending on their pre-existing regimens. Perioperatively, $34.4 \%$ (n $=33$ ) were already on antiepileptics for post-traumatic seizures. Phenytoin was the most commonly administered perioperative antiepileptic in $20.8 \%(\mathrm{n}=20)$ of the patients. Drug levels were checked and brought to therapeutic levels in all patients prior to surgery.

The defect was reconstructed using saved autologous bone in $67.7 \%(\mathrm{n}=65)$ of the patients, $15.6 \%(\mathrm{n}=$ 15) had a bone fashioned using PMMA, $11.5 \%$ ( $\mathrm{n}=$ 11) had their autologous bone used along with PMMA, and $5.2 \%(\mathrm{n}=5)$ had their bone flap autoclaved prior to replacement. The flaps were secured using silk sutures $(33.3 \%, \mathrm{n}=32)$, vicryl sutures $(27.1 \%, \mathrm{n}=26)$, titanium plates $(19.8 \%, \mathrm{n}=19)$, or wires $(18.8 \%, \mathrm{n}=18)$. Galeal closures were done using absorbable vicryl in all patients and skin was closed using either sutures $(69.8 \%, \mathrm{n}=67)$ or staples $(30.2 \%, \mathrm{n}=29)$ depending upon the surgeons' preference. Subgaleal drains were placed prior to closure in $28.1 \%(\mathrm{n}=27)$ of the patients and no patient underwent placement of an epidural or subdural drain. The mean duration of surgery was $185.2 \pm 67.3$ minutes, resulting in an average blood loss of $365 \pm 263 \mathrm{ml}$. Seventeen patients $(17.7 \%)$ required intraoperative blood transfusions and mean duration of hospital stay was $12 \pm$ 17 days.
In a mean follow up of $386 \pm 615$ days, complications were noted in $36.5 \%(\mathrm{n}=35)$ of the patients. The complications were divided into major and minor complications. Minor complications accounted for 29.1\% $(\mathrm{n}=25)$ including most notably, breakthrough seizures $(15.6 \%, n=15)$, CSF leak $(4.1 \%, n=4)$, postoperative subgaleal fluid collections other than that caused by underlying hydrocephalus $(3.1 \%, \mathrm{n}=3)$, superficial wound infections (SWI) $(3.1 \%, \mathrm{n}=3)$, and new-onset transient neurological deficits $(3.1 \%, \mathrm{n}=3)$ [Figure 1]. Major complications accounted for $7.3 \%(\mathrm{n}=10)$ and included hydrocephalus $(3.1 \%, \mathrm{n}=3)$, osteomyelitis $(2.1 \%, \mathrm{n}=2)$, SDH $(1 \%, \mathrm{n}=1)$, and $\mathrm{EDH}(1 \%, \mathrm{n}=1)$ [Figure 2]. The mean GCS on follow-up was $14.34 \pm$ 1.5 and $9.33 \pm 1.15$ for the patients on tracheostomies. The complications required seven (7.3\%) repeat surgeries, including three for ventriculoperitoneal shunt

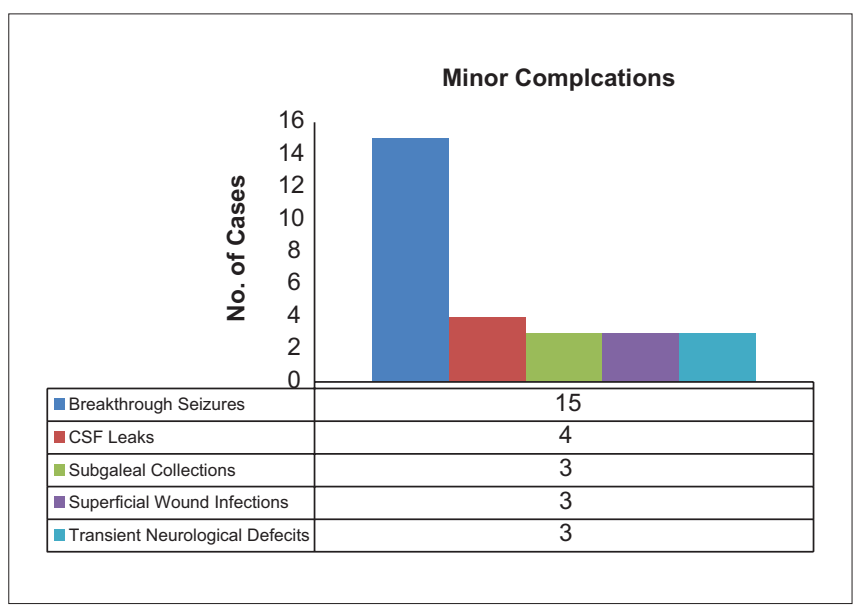

Figure I: Summary of the minor complications noted in the study population. Blue: Breakthrough seizures, Red: CSF Leaks, Olive: Subgaleal Collections, Purple: Superficial wound infections and Light blue:Transient Neurological Defecits

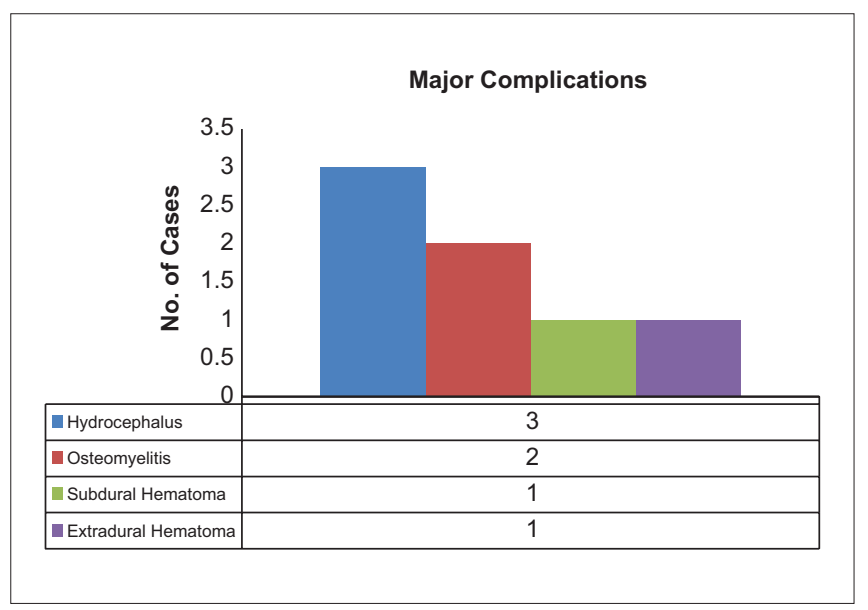

Figure 2: Summary of the major complications noted in the study population. Blue: Hydrocephalus, Red Osteomyelitis, Olive: Subdural Hematoma and Purple: Extradural Hematoma 
insertions, two for debridement of osteomyelitis, and two craniotomies, one each for SDH and EDH.

Univariate regression analysis revealed that External Ventricular Drain (EVD) placement prior to reconstructive cranioplasty was $4.2(0.98-18.1, P=0.05)$ times more likely to be associated with complications. When considering the flap sites, parietal flaps were 6.11 (1.20-31.16) times more likely to be associated with complications compared with frontal flaps. Other factors were not associated with significant odds of complication [Table 1]. Although of only borderline significance, autoclaved autologous bone when used was nine times (0.95-85.71, $P=0.06)$ more likely to be associated with complications when compared with autologous bone used without autoclaving. A multivariate analysis model including age, comorbidities, number of cranial procedures, flap site, EVD placement, GCS on admission, primary pathology, method of preservation of bone, delay in surgery, material used to secure the bone, and subgaleal drain placement was created. Multivariate analysis showed that EVD placement was 10.1 (1.13-90.20) times more likely to be associated with complications. None of the other findings were significant on multivariate analysis [Table 1].

\section{DISCUSSION}

It is apparent from the growing body of evidence that decompressive craniectomies will be a significant part of neurosurgical practice and so will be the requirement of cranioplasties. However, integral the reconstructive procedure may be, there have been few studies that have actually addressed the issue and no comprehensive guidelines are available regarding the technique and timing of the procedure, especially with respect to the possible complications. ${ }^{[7,10,16]}$ Current practices relating to cranioplasties are subjective and based either on the surgeon's preferences or institutional policies and there is a void of literature on practices that can potentially minimize the risk of complications. . $^{[3,22]}$

We have presented one of the largest series of postdecompressive craniectomy cranioplasties with a mean follow-up of more than one year. To the best of our knowledge, no previous study has analyzed more preoperative variables than ours. Moreover, we have primarily used autologous bone, saved at negative $26^{\circ} \mathrm{C}$ with acceptable rates of infection, thus supporting recent reports that freezing bone flaps at lower temperatures may not be necessary. ${ }^{[22]}$ In our mean follow-up of over one year, we found the complication rate to be high at around $36.5 \%$, with $7 \%$ requiring surgical interventions for their complications. Of these complications, 29.1\% (n $=25$ ) were minor complications including breakthrough seizures, CSF leak, postoperative subgaleal fluid collections, new-onset deficits, and SWI. However, 7.3\% $(\mathrm{n}=10)$ patients had severe complications including hydrocephalus, osteomyelitis, SDH, and EDH. Although the neurological deficits in all three cases were transient and recovered completely over the next three weeks, we have categorized it as a major complication. Similarly, postoperative subgaleal fluid collections even though are not generally considered a complication, it is a source of significant discomfort to the patient and we have included it as a minor complication to be able to study possible predisposing factors. Although another paper has reported postoperative fluid collections including EDH and subgaleal collections necessitating operative interventions in 13 of $212(6.1 \%)$ patients and found a difference in the rate of fluid collection complications with and without drain placement, with a trend toward significance $(P=0.065)$, we found no statistically meaningful relationship between intraoperative placement of subgaleal vacuum drains and occurrence of postoperative subgaleal fluid collections $(P=0.99)$.

Our study shows that an EVD placement prior to the reconstructive procedure was more likely to be associated with complications. This can be explained by the fact that the nine patients requiring EVD placement had relatively severe injuries resulting in an increased risk of complications. Further studies on larger cohorts will be required to validate this particular observation before any definite conclusions could be drawn. Our study revealed that parietal bone flaps were associated with higher complications. However, this could be explained by the fact that patients undergoing parietal flaps in our dataset mainly constituted those undergoing index surgeries due to penetrating head trauma or tumor surgeries at the site, which are inherently associated with a higher rate of complications.

A $36.5 \%$ risk of complications may appear high but it may be noted that other centers have reported similarly high complication rates ranging between $16.4 \%$ and $34 \%$. $5,9,19]$ Moreover, these studies have not considered postoperative subgaleal fluid collection or transient neurological deficits as complications. In fact, few studies have also not considered breakthrough seizures as complications. One of the largest study to date comprising of 212 patients found an increased risk of complications when patient age exceeded 40 years, in cases operated for reasons other than trauma, especially tumors and an interval period of greater than three months between index surgery and cranioplasty. However, we were not able to validate any of these findings in our study. Although we did not include cranioplasties done for tumor involved bone flaps as they did, one can assume the risk of complications to be higher in this particular sub group due to immunocompetent status of patients and concomitant chemo and radiation therapy. Others have also reported complication rates for cranioplasty to be paradoxically high when done following surgery for trauma. ${ }^{[19]}$ Most 
Table 1: Summary of factors assessed for possible associations with complications

\begin{tabular}{|c|c|c|c|c|c|}
\hline \multirow[t]{2}{*}{ Variable } & \multirow[t]{2}{*}{ Categories } & \multirow{2}{*}{$\begin{array}{c}\text { Frequency } \\
\mathrm{N}(\%)\end{array}$} & \multirow{2}{*}{$\frac{\text { Complications }}{\text { N (\%) }}$} & \multicolumn{2}{|c|}{ Univariate results } \\
\hline & & & & OR & $95 \% \mathrm{Cl}$ \\
\hline \multirow[t]{2}{*}{ Gender } & Male & $70(73)$ & $25(36)$ & 1 & - \\
\hline & Female & $26(27)$ & $9(35)$ & 0.95 & $0.37,2.5$ \\
\hline Age & - & - & - & 0.99 & $0.96,1.02$ \\
\hline \multirow[t]{2}{*}{ Number of procedures } & Single & $57(60)$ & $16(28)$ & 1 & - \\
\hline & Multiple & $39(41)$ & $18(46)$ & 2.20 & $0.94,5.2$ \\
\hline \multirow[t]{2}{*}{ Flaps } & Unilateral & $80(83)$ & $30(38)$ & 1 & - \\
\hline & Bilateral & $16(17)$ & $4(25)$ & 0.56 & $0.16,1.88$ \\
\hline \multirow[t]{2}{*}{ EVD } & No & $87(91)$ & $28(32)$ & 1 & - \\
\hline & Yes* & $9(9)$ & $6(67)$ & 4.2 & $0.98,18.1$ \\
\hline \multirow[t]{4}{*}{ Surgical site } & Frontal & $17(17)$ & $6(35)$ & 1 & - \\
\hline & Parietal* & $13(14)$ & $10(77)$ & 6.11 & $1.20,31.16$ \\
\hline & Temporal & $9(9)$ & $3(33)$ & 0.92 & $0.17,5.05$ \\
\hline & Trauma Flap & $57(59)$ & $15(26)$ & 0.66 & $0.21,2.1$ \\
\hline \multirow[t]{3}{*}{ Flap preservation } & Subcutaneous & $9(9)$ & $3(33)$ & 1 & - \\
\hline & Cryopreservation & $73(76)$ & $24(33)$ & 1.02 & $0.24,4.4$ \\
\hline & Damaged/Discarded & $14(15)$ & $7(50)$ & 2.04 & $0.64,6.5$ \\
\hline \multirow[t]{2}{*}{ Tracheostomy } & No & $65(68)$ & $22(34)$ & 1 & - \\
\hline & Yes & $32(32)$ & $12(38)$ & 1.2 & $0.51,3.00$ \\
\hline \multirow[t]{2}{*}{ PEG } & No & $85(89)$ & $31(36)$ & 1 & - \\
\hline & Yes & $11(12)$ & $3(27)$ & 0.65 & $0.16,2.6$ \\
\hline \multirow[t]{2}{*}{ Preoperative antiepileptic drug } & No & $63(65)$ & $20(32)$ & 1 & - \\
\hline & Yes & $23(25)$ & $14(61)$ & 1.58 & $0.66,3.78$ \\
\hline \multirow[t]{4}{*}{ Cranioplasty material } & Autologous bone & $65(68)$ & $20(31)$ & 1 & - \\
\hline & Bone autoclaved & $5(5)$ & $4(80)$ & 9 & $0.95,85.71$ \\
\hline & PMMA & $15(16)$ & $7(47)$ & 2.00 & $0.63,6.2$ \\
\hline & PMMA + Bone & $11(12)$ & $3(27)$ & 0.84 & $0.20,3.52$ \\
\hline \multirow[t]{4}{*}{ Bone secured with } & Silk & $33(33)$ & $12(36)$ & 1 & - \\
\hline & Vicryl & $26(27)$ & $7(27)$ & 0.65 & $0.21,1.98$ \\
\hline & Plates & $19(20)$ & $10(53)$ & 1.94 & $0.62,6.12$ \\
\hline & Wires & $18(19)$ & $5(28)$ & 0.67 & $0.19,2.35$ \\
\hline \multirow[t]{2}{*}{ Subgaleal drain placed } & No & $69(72)$ & $27(39)$ & 1 & - \\
\hline & Yes & $27(28)$ & $7(26)$ & 0.54 & $0.20,1.45$ \\
\hline \multirow[t]{2}{*}{ Skin closure } & Staples & $29(30)$ & $12(41)$ & 1 & - \\
\hline & Sutures & $67(70)$ & $22(33)$ & 0.69 & $0.28,1.70$ \\
\hline \multirow[t]{2}{*}{ Intraoperative transfusion } & No & $79(82)$ & $27(34)$ & 1 & - \\
\hline & Yes & $17(18)$ & $7(41)$ & 1.35 & $0.46,3.94$ \\
\hline \multirow[t]{3}{*}{ Preoperative GCS } & $3-8$ & $9(9)$ & $4(44)$ & 1.41 & $0.34,5.83$ \\
\hline & $9-12$ & $29(30)$ & $9(31)$ & 0.79 & $0.31,2.05$ \\
\hline & $13-15$ & $58(60)$ & $21(36)$ & 1 & - \\
\hline \multirow[t]{2}{*}{ Comorbids } & No & $73(76)$ & $24(33)$ & 1 & - \\
\hline & Yes & $23(24)$ & $10(43)$ & 1.57 & $0.60,4.1$ \\
\hline Primary pathology & TBI Blunt & $44(46)$ & $18(41)$ & 1 & - \\
\hline & TBI Penetrating & $11(12)$ & $4(36)$ & 0.83 & $0.43,3.45$ \\
\hline & Tumor & $10(10)$ & $6(60)$ & 2.2 & $0.74,3.50$ \\
\hline & Infection & $8(8)$ & $0(0)$ & - & - \\
\hline & Vascular & $23(24)$ & $6(26)$ & 0.51 & $0.17,1.54$ \\
\hline Delay between index surgery & $0-30$ & $25(26)$ & $9(36)$ & 1 & - \\
\hline and cranioplasty (days) & $31-90$ & $46(48)$ & $16(35)$ & 0.95 & $0.34,2.62$ \\
\hline & $>90$ & $25(26)$ & $9(36)$ & 1.00 & $0.32,3.17$ \\
\hline
\end{tabular}


Table 1: Contd...

\begin{tabular}{|c|c|c|c|c|c|}
\hline \multirow[t]{2}{*}{ Variable } & \multirow[t]{2}{*}{ Categories } & \multirow{2}{*}{$\begin{array}{c}\text { Frequency } \\
\mathbf{N}(\%)\end{array}$} & \multirow{2}{*}{$\frac{\text { Complications }}{\text { N (\%) }}$} & \multicolumn{2}{|c|}{ Univariate results } \\
\hline & & & & OR & $95 \% \mathrm{Cl}$ \\
\hline \multirow[t]{2}{*}{ Preoperative hemoglobin } & Low & $72(75)$ & $25(35)$ & 1 & - \\
\hline & Normal & $24(25)$ & $9(38)$ & 1.13 & $0.43,2.94$ \\
\hline \multirow[t]{2}{*}{ Other drains used } & No & $82(85)$ & $30(37)$ & 1 & - \\
\hline & Yes & $14(15)$ & $4(29)$ & 0.69 & $0.20,2.40$ \\
\hline \multirow[t]{3}{*}{ Intraoperative blood loss } & $<250$ & $44(46)$ & $15(34)$ & 1 & - \\
\hline & $250-500$ & $32(34)$ & $11(34)$ & 1.01 & $0.39,2.64$ \\
\hline & $>500$ & $19(20)$ & $7(37)$ & 1.13 & $0.37,3.45$ \\
\hline \multirow[t]{2}{*}{ Postoperative antibiotic duration } & Up to 7 days & $59(62)$ & $22(37)$ & 1 & - \\
\hline & $>7$ days & $37(39)$ & $12(32)$ & 0.81 & $0.34,1.92$ \\
\hline
\end{tabular}

EVD: External Ventricular Drain, PEG: Percutaneous Endoscopic Gastrostomy, GCS: Glasgow coma scale

recently reported data are of 69 patients of post-trauma decompression and later cranioplasty, which although reported only two complications, but both with relatively high frequencies; infections in $18.8 \%$ and hydrocephalus in $20.2 \%$ patients. ${ }^{[2]}$ Their paper also highlighted that autologous bone grafting had a lower risk of infections. ${ }^{[5]}$ As per their institutions policy, all bone grafts were cryopreserved and autoclaved prior to replacement [Mehmood A, Personal Communication]. Although of only borderline significance (univariate analysis, $P$ $=0.06$; multivariate analysis, $P=0.09$ ), we saw an increased odds of complications with autologous bone when it was autoclaved. Similarly, we found no difference in the probability of complications with the type of material used for securing bone (various types of suture or titanium plates), method of bone preservation, use of synthetic material for cranioplasty, interval period of three months or longer between index surgery and cranioplasty, etc. A recent systematic review, which only addressed post-cranioplasty infections and incorporated data from five decades, also found no associations between the aforementioned factors and the risk of infection. ${ }^{[22]}$

\section{Limitations}

The study was carried out as a retrospective.

\section{CONCLUSION}

When undergoing a cranioplasty for decompressive craniectomy, we have found a higher risk of complications in patient who had an EVD at the time of decompressive surgery. We however did not find any association between risk of complications and age of patient, presence of comorbids, time interval between the two surgeries, the method of flap preservation, the type of material used for plasty, i.e., autograft $v s$ allograft, or the material used to secure the bone flap, or any of the other variables studied. Overall, our results are comparable with other reported series on cranioplasties. It will therefore suffice to say that in its rich history of nearly 400 years, from the initial gold plates of Fallopius and the first bone graft by Meekeren, ${ }^{[16]}$ cranioplasties still have a long way to evolve in terms of patient safety. Larger studies are needed where the associations of these complications can be clearly defined and set protocols derived in order to help minimize the risk of complications.

\section{REFERENCES}

I. Aarabi B, Hesdorffer DC, Simard JM, Ahn ES, Aresco C, Eisenberg HM, et al. Comparative study of decompressivecraniectomy after mass lesion evacuation in severe head injury. Neurosurgery 2009;64:927-39; discussion 939-40.

2. Beauchamp KM, Kashuk J, Moore EE, Bolles G, Rabb C, Seinfeld J, et al. Cranioplasty after postinjurydecompressivecraniectomy: Is timing of the essence? J Trauma 2010;69:270-4.

3. Bhaskar IP, Zaw NN, Zheng M, Lee GY. Bone flap storage following craniectomy:A survey of practices in major Australian Neurosurgical centres. ANZ J Surg 201 I;8I:I37-4I.

4. Bullock MR, Chesnut R, Ghajar J, Gordon D, Hartl R, Newell DW, et al.Surgical management of traumatic parenchymal lesions. Neurosurgery 2006;58 Suppl 3:S25-46; discussion SI-4.

5. ChangV, Hartzfeld P, Langlois M, Mahmood A, Seyfried D. Outcomes of cranial repair after craniectomy. J Neurosurg 2010; I I2: I I 20-4.

6. Colohan AR, Ghostine S, Esposito D. Exploring the limits of survivability: Rational indications for decompressivecraniectomy and resection of cerebral contusions in adults. Clin Neurosurg 2005;52:19-23.

7. Datti R, Cavagnaro G, Camici S. Stainless steel wire mesh cranioplasty:Ten years' experience with 183 patients (100 followed up). Acta Neurochir (Wien) 1985;78:133-5.

8. Dujovny M, Fernandez P, Alperin N, Betz W, Misra M, Mafee M. Postcranioplasty cerebrospinal fluid hydrodynamic changes: Magnetic resonance imaging quantitative analysis. Neurol Res 1997; 19:3 I I-6.

9. Gooch MR, Gin GE, Kenning TJ, German JW. Complications of cranioplasty following decompressivecraniectomy:Analysis of 62 cases. Neurosurg Focus 2009;26:E9.

10. Jho DH, Neckrysh S, Hardman J, Charbel FT,Amin-Hanjani S. Ethylene oxide gas sterilization:A simple technique for storing explanted skull bone.Technical note. J Neurosurg 2007; 107:440-5.

II. Juttler E, Schwab S, Schmiedek P, Unterberg A, Hennerici M, Woitzik J, et al. Decompressivesurgery for the treatment of malignant infarction of the middle cerebral artery (DESTINY): A randomized, controlled trial. Stroke 2007;38:2518-25.

12. Ma L, LiuWG, Sheng HS, Fan J, HuWW, Chen JS. Decompressivecraniectomy in addition to hematoma evacuation improves mortality of patients with spontaneous basal ganglia hemorrhage. J Stroke Cerebrovasc Dis 2010;19:294-8. 
13. Meier U, Grawe A, Konig A. The importance of major extracranial injuries by the decompressivecraniectomy in severe head injuries. Acta Neurochir Suppl 2005;95:55-7.

14. Merenda A, DeGeorgia M. Craniectomy for acute ischemic stroke: How to apply the data to the bedside. Curr Opin Neurol 2010;23:53-8.

15. Sahuquillo J, Arikan F. Decompressivecraniectomy for the treatment of refractory high intracranial pressure in traumatic brain injury. Cochrane Database Syst Rev 2006:CD003983.

16. Sanan A, Haines SJ. Repairing holes in the head: A history of cranioplasty. Neurosurgery 1997;40:588-603.

17. Skoglund TS, Eriksson-Ritzen C, Jensen C, Rydenhag B. Aspects on decompressivecraniectomy in patients with traumatic head injuries. J Neurotrauma 2006;23:1502-9.

18. Smith ER, Carter BS, Ogilvy CS. Proposed use of prophylactic decompressivecraniectomy in poor-grade aneurysmal subarachnoid hemorrhage patients presenting with associated large sylvian hematomas. Neurosurgery 2002;51:I 17-24; discussion I24.
19. Stephens FL, Mossop CM, Bell RS, Tigno T Jr, Rosner MK, Kumar A, et al. Cranioplasty complications following wartime decompressivecraniectomy. Neurosurg Focus 2010;28:E3.

20. Unterberg A, Juettler $\mathrm{E}$. The role of surgery in ischemic stroke: Decompressivesurgery. Curr Opin Crit Care 2007;13:175-9.

21. Vahedi K, Vicaut E, Mateo J, Kurtz A, Orabi M, Guichard JP, et al. Sequential-design, multicenter, randomized, controlled trial of early decompressivecraniectomy in malignant middle cerebral artery infarction (DECIMAL Trial). Stroke 2007;38:2506-I7.

22. Yadla S, Campbell PG, Chitale R, Maltenfort MG, Jabbour P, Sharan AD. Effect of early surgery, material, and method of flap preservation on cranioplasty infections: A systematic review. Neurosurgery 20 I 1;68: I I24-9; discussion 1130.

23. Yamaura A, Makino H. Neurological deficits in the presence of the sinking skin flap following decompressivecraniectomy. Neurol Med Chir (Tokyo) 1977; 17:43-53. 